\title{
LA RED URBANA ARAGONESA: ENTRE EL SISTEMA URBANO ESTATAL Y LOS SUBSISTEMAS PROVINCIALES
}

\author{
Vicentc BIELZA DE ORY \\ Javier CALLIZO SONEIRO \\ $\mathrm{Y}$ \\ Severino ESCOLANO UTRILLA
}

Universidad de Zaragoza

La evolución de la estructura territorial de la Administración del Estado con el advenimiento de los Borbones, el impacto de la revolución industrial a partir del siglo XIX y la incidencia de la política franquista son claves de una dialéctica ya centenaria entre un sistema urbano estatal, inexistente antes del siglo XVIII, y los subsistemas urbanos regionales cuya virtualidad, ante el hecho insoslayable de la División Provincial decimonónica, iba a quedar en muchos casos seriamente comprometida, toda vez que la ley de Javier de Burgos propiciaría la génesis de subsistemas urbanos acomodados a los límites de la nueva demarcación administrativa.

Si el tema es de suyo apasionante, en el caso de Aragón cobra una vigencia renovada: en las circunstancias "autonómicas" actuales, nuestra Comunidad se enfrenta al reto de reconstruir un subsistema urbano que era realidad sólida antes de la Guerra de Sucesión, pero que quedó diluído entre el sistema urbano estatal que comienza a gestarse con Felipe $V$ y el hecho provincial salido de la División de 1833. Es el objeto del presente trabajo.

Para ello, y a modo de apunte metodológico, vamos a servimos de le ley "rango-tamaño". La formulación de Zipf ha suscitado no pocas críticas; se la ha motejado de simple, lo cual no es sino principio básico de todo modelo; de pura contingencia (Derycke, 1970, pp. 72-73); de exclusivamente economicista (García Nieto, 1983, p. 54); de "rcgularidad cmpírica" más que de "esquema lógico" (Fulvi, 1985, p. 49), etc... Lo cierto es que, sin menoscabo de estos y otros juicios de valor, conducido con la prudencia necesaria, el modelo permite mostrar -y además de forma secuencial, lo que para un cstudio evolutivo como el que nos ocupa cs más que conveniente- la 
variación temporal de la relación existente entre la distribución real de una jerarquía de ciudades y la esperada o lognormal segun la teoría. Su validez ha quedado plenamente confirmada. $Y$ en cualquier caso resulta ser un muy estimable método de diagnosis (Gucrra Zaballos, 1981).

1.- EL SUBSISTEMA URBANO ARAGONES EN TANTO QUE PARTE DEL SISTEMA URBANO ESPAÑOL PREINDUSTRIAL.

\section{1.- La definición de sistema y subsistema tradicionales.}

Antes de la revolución de la industria y los transportes y antes de la creación de las provincias, la configuración del sistema urbano español estaba condicionada por toda una serie de factores relacionados con la historia socioeconómica española, de suerte que el sistema urbano estatal comprendía subsistemas urbanos correspondientes a los antiguos reinos medievales: tal era el caso del Reino de Aragón.

La unidad de España, inspirada por los Reyes Católicos, se llevó a cabo respetando la entidad política de los reinos medievales. La unidad de España fue concebida por la Casa de Austria a partir de la diversidad de los reinos, sin eliminar por tanto las fronteras político-administrativas. Esto permitió el nacimiento de un sistema urbano español que, en el marco socioeconómico de la época, iba a integrar progresivamente los sistemas urbanos de los antiguos reinos en tanto que subsistemas. De esta manera, las relaciones entre Zaragoza y Madrid se fortalecían sin que por ello se deteriorasen las relaciones entre Zaragoza y las otras ciudades aragonesas.

El trazado de las comunicaciones de la Edad Moderna, en España, contribuye a perpetuar la cohesión interna de los subsistemas regionales. No existe todavía el trazado radial a partir de Madrid, que privilegia estos ejes sobre los demás. Las vías de comunicación, que no corren todavía a cargo del Estado, son generalmente cortas, adaptadas al medio físico (valles) o a las necesidades de la trashumancia: las cabañeras y los senderos de montaña o de la llanura eran utilizados para los intercambios comerciales. En el interior de cada región histórica (antiguo reino), existen relaciones socioeconómicas internas que se anudan en las cabeceras comarcales, en particular en torno a los mercados semanales de origen medieval. 


\section{2.- Aplicación del modelo "rango-tamaño" a fines del siglo XVIII.}

La validez del modelo "rango-tamaño" exige previamente que los elementos urbanos considerados constituyan un verdadero sistema $o$ subsistema. Según cuanto ha sido dicho en los párrafos precedentes, y como hipótesis de partida, es lógico hablar, a fines del siglo XVIII, de un sistema urbano español y de subsistemas urbanos regionales, correspondientes a los antiguos reinos, en el interior de los cuales se distinguen además nucvas unidades de carácter regional o subrcgional.

A fines del siglo XVIII, el sistema urbano español correspondía, si se considera la parte superior de la jerarquía urbana, al modelo de Zipf. En la cúspide aparece Madrid, con un población -según Vicens Vives- de 167.000 habitantes; en segundo lugar, Barcelona, que, gracias a un fuerte crecimiento en el transcurso de este siglo (1), sobrcpasa los 150.000; y ya a continuación, Sevilla, Valencia, y Granada, que se aproximan a los 100.000 habitantes; Cádiz contaba 70.000, mientras que Málaga y Zaragoza se situaban alrededor de los 50.000 habitantes. Las ciudades del norte de España cran menos populosas y aparecían muy lejos en cl ranking español: Bilbao contaba 12.000 habitantes, Gijón y Vigo 6.000...

Zaragoza era ya una de las primeras ciudades del sistema urbano español y constituía la ciudad primate del subsistema urbano aragonés. El rank-size aplicado a los núclcos de población de más de 2.000 habitantes (2), según el Censo de 1787, nos da la distribución que aparece $\mathrm{cn}$ el Cuadro $\mathrm{n}^{\mathrm{O}} 1$.

En la distribución de 1787 se observa la existencia de un fuerte índice de primacía (próximo a 5) entre Zaragoza y la ciudad siguiente del subsistema Calatayud-, y, de una manera general, una cierta desviación de la población real de Zaragoza por encima de la población teórica que le correspondería en una distribución normalizada conforme al modelo. Las desviaciones negativas aparecen en las ciudades de tipo medio: Calatayud, Tarazona, Huesca, Teruel y Caspe, mientras que las pequeñas, los núclcos de carácter semiurbano, presentan desviaciones positivas. En el conjunto, se puede deducir que el tamaño de Zaragoza era superior al esperable en tanto que cabecera del subsistema aragonés, lo que cs conforme con un pasado en el que Zaragoza fue la ciudad central de una Corona que organizaba un territorio y por consiguiente de las ciudades allende los límiles de Áragón. 


\section{7 \\ CUADRO I: "RANK-SIZE" DE LA REGION ARAGONESA.}

\begin{tabular}{lcccc} 
NºIUDAD & POBLAC. & POBLAC. & $\begin{array}{c}\text { DESVIACION } \\
\text { DIF. }\end{array}$ & $\begin{array}{c}\text { DESVIACION } \\
\text { DIF. }\end{array}$ \\
& REAL & TEORICA & ABSOL & RELAT \\
\hline 1.Zaragoza & 42600 & 37830 & 4769 & 12.6 \\
2.Calatayud & 8544 & 18915 & -10372 & -54.9 \\
3.Tarazona & 6954 & 12610 & -5657 & -44.9 \\
4.Huesca & 6885 & 9458 & -2573 & -27.3 \\
5.Teruel & 6270 & 7566 & -1297 & -17.2 \\
6.Caspe & 6071 & 6305 & -235 & -3.8 \\
7.Alcañiz & 5542 & 5404 & 137 & 2.5 \\
8.Barbastro & 5318 & 4729 & 589 & 12.4 \\
9.Fraga & 3908 & 4203 & -296 & -7.1 \\
10Albalate del Arzobispo & 3670 & 3783 & -114 & -3.0 \\
11.Belchite & 3614 & 3439 & 174 & 5.0 \\
12.Borja & 3588 & 3153 & 435 & 13.8 \\
13.La Almunia de Dña. Godina & 3256 & 2910 & 345 & 11.8 \\
14.Calanda & 3020 & 2702 & 317 & 11.7 \\
15.Tauste & 3016 & 2522 & 493 & 19.5 \\
16.Monzón & 2871 & 2364 & 506 & 21.4 \\
17.Epila & 2851 & 2225 & 625 & 28.1 \\
18.Daroca & 2822 & 2102 & 720 & 34.2 \\
19.Tamarite de Litera & 2698 & 1991 & 706 & 35.5 \\
20.Ejea de los Caballeros & 2625 & 1892 & 733 & 38.7 \\
21.Ateca & 2555 & 1801 & 753 & 41.8 \\
22.Sos del Rey Católico & 2448 & 1720 & 728 & 42.3 \\
23.Uncastillo & 2246 & 1645 & 601 & 36.5 \\
24.Calaceite & 2244 & 1576 & 667 & 42.3 \\
25.Mora de Rubielos & 2229 & 1513 & 715 & 47.3 \\
26.Alagón & 2188 & 1455 & 732 & 50.3 \\
27.Hínar & 2164 & 1401 & 762 & 54.4 \\
28.Maella & 2154 & 1351 & 802 & 59.4 \\
29.Rubielos de Mora & 2143 & 1304 & 838 & 64.2 \\
30.Samper de Calanda & 2140 & 1261 & 878 & 69.7 \\
31.Cariñena & 2036 & 1220 & 815 & 66.8 \\
32.Albarracín & 2005 & 1182 & 822 & 69.6 \\
33.Mosqueruela & 2005 & 1146 & 858 & 74.9 \\
TOTAL POBLAClON & 154680 & & & \\
& & & &
\end{tabular}


INDICE DE PRIMACIA $1=4,985$

INDICE DE PRIMACIA $2=2,748$

INDICE DE PRIMACIA $3=1,903$

INDICE DE PRIMACIA $4=1,486$

\section{2.- EL DECLIVE DE LOS SUBSISTEMAS URBANOS REGIONALES Y EL REFUERZO DEL SISTEMA URBANO ESTATAL}

\subsection{Los factores políticos y económicos.}

La política, tanto borbónica como napoleónica, uniformista y centralista respecto de la organización territorial del Estado, favoreció el declive de los subsistemas urbanos de carácter regional en beneficio del refuerzo del sistema urbano central. La revolución industrial dio lugar al desarrollo de ciertos núcleos de concentración humana que ganaron posiciones en el ranking urbano español.

\subsection{1.- Las reformas político-administrativas.}

El uniformismo borbónico, inaugurado por Felipe $\mathrm{V}$ con los "Edictos de Nueva Planta", significa la ruptura con la filosofía política de la Casa de Austria: a partir de ahora, la unidad de España será concebida desde la uniformidad de los antiguos reinos integrantes. Las aduanas de cada territorio -los puertos secos- fueron suprimidas, lo que propició la génesis progresiva de un mercado nacional; la división administrativa de Castilla con territorios bajo la tutela de un corregidor se impuso en la antigua Corona de Aragón; los nombramientos para los puestos municipales fueron hechos por designación del Gobierno central; la organización de la vida económica fue centralizada en Madrid. Estas medidas provocaron, por el hecho de la ampliación del espacio económico (Lasuén, 1986, pp. 131-133), el desarrollo económico de los territorios de la ex-Corona aragonesa, pero, al mismo tiempo, la pérdida de las relaciones internas en el seno de cada región.

En el transcurso del siglo XVIII, Aragón conservó su unidad administrativa dividida en territorios bajo la tutela de corregidores, lo que hace que, a finales de siglo, Zaragoza y las demás cabeceras de corregimiento (Albarracín, Alcañiz, Barbastro, Benabarre, Borja, Calatayud, Sos, Daroca, Huesca, Jaca, Tarazona, Teruel) mantengan todavía el entramado de relaciones propias de un sistema urbano. 
La influcncia napoleónica exaccrbó el centralismo de los Borbones. A comienzos del siglo XIX hubo varios intentos de reforma administrativa (las prefecturas de 1810 , las provincias de 1822), que cristalizaron en $1833 \mathrm{en}$ forma de un Real Decreto de 30 de Noviembre, mediante el que se ordena la división del territorio en provincias. En cl artículo 1, "el territorio español está dividido en 49 provincias"; en cl artículo 2, ..."Aragón está dividido en tres provincias, a saber: Zaragoza, Huesca y Tcruel..." Esta división supone la desaparición administrativa de Aragón, que con antcrioridad había sucumbido ya políticamente. Es un clemento que es preciso tener en cuenta para explicar el declive progresivo del "sistema"urbano aragonés, todavía en vigor, y la lenta aparición de subsistemas provinciales en el seno de un sistema progresivamente estatal.

En 1834, otro Real Decreto ordena la creación -a partir de las provinciasde los partidos judiciales, lo que contribuye a reforzar una serie de núcleos urbanos en su papel de lugares centrales. En Aragón, las cabezas de partido judicial reconocidas en el Decreto en cuestión fueron las siguientes: HUESCA: Barbastro, Benabarre, Boltaña, Fraga, Huesca, Jaca y Sariñena; TERUEL: Albarracín, Alcañiz, Aliaga, Calamocha, Castellotc, Híjar, Mora, Segura, Teruel y Valderrobres; ZARAGOZA: La Almunia, Ateca, Belchite, Borja, Calatayud, Caspe, Daroca, Ejea, Pina, Sos, Tarazona y Zaragoza .

El esquema administrativo y territorial a partir de 1833-34 no resulta tan simple como lo hubiera querido su autor, Javier de Burgos, dado que esta división no fue seguida ulteriormente por todas las instancias de la Administración. En el artículo 4 del Decreto de 1833 se decía: "...esta División de las Provincias no se limitará exclusivamente al terreno administrativo, sino que a ella deberán ajustarse también las demarcaciones militares, judiciales y fiscales". Ahora bien, como el Ministerio del Interior perdiera la competencia exclusiva sobre las divisiones territoriales de carácter especial, cada ministerio dividió el territorio como más oportuno lo juzgó para la organización de sus servicios. Lo que tuvo como consecuencia que Zaragoza, habiendo perdido competencias administrativas globales en relación a Huesca y Teruel, recibió, por el hecho de haberse dividido el territorio español a medida de cada ministerio, competencias parciales que sobrepasaban los límites históricos de Aragón. Entiéndese así que a mediados del siglo XX el Estado Mayor de la V Región Militar -que, hasta hace unos meses, en que se ha puesto en marcha una nueva división militar del territorio, englobaba las tres provincias aragonesas y Soria-, la Región Aérea Pirenaica -que comprendía las provincias de Huesca y Zaragoza, así como las catalanas- , el Distrito Universitario de Zaragoza -que comprendía las tres provincias aragonesas, Soria, Logroño y Navarra- y la Audiencia 
Territorial -que era la única que cubría exactamente la región aragonesactuvieran su sede en Zaragoza.

En general, se puede afirmar que la reforma político-administrativa contribuye al deterioro del sistema urbano aragonés, permite la lenta gestación de débiles subsistemas provinciales y acentúa la macrocefalia de Zaragoza.

\subsubsection{La alteración sustancial del trazado viario.}

La organización, estructura y relaciones de las ciudades que integran un sistema urbano dependen, en gran parte, del trazado de la red de comunicaciones, que favorece las relaciones recíprocas; por lo que juzgamos muy importante el análisis de los cambios producidos a partir del siglo XVIII. Una de las más claras manifestaciones del centralismo borbónico se advierte en la sustitución del trazado caminero, viejo y de escasa envergadura, por otro de carácter radial controlado desde Madrid. La normativa de 1747 asignaba por vez primera al Estado la responsabilidad de construir los caminos a cargo del tesoro público. En 1760 quedó ultimado el "Proyecto económico de Bernard Ward" en el que podía leerse: "España necesita seis grandes caminos, de Madrid a la Coruña, Badajoz, Cádiz, Alicante y a la frontera con Francia, bien por Bayona, bien por Perpiñán" En el transcurso de los primeros años del siglo XIX las seis carreteras radiales estaban prácticamente terminadas. En el caso de Aragón, con la construcción de la carretera Madrid-Barcelona, las ciudades del valle medio del Jalón -Calatayud, por ejemplo- y sobre todo Zaragoza verán reforzado su papel: doblemente en el caso de ésta última cuando, más adelante, sean construídas, desde Cataluña y Valencia, las carreteras hacia el País Vasco.

El plan general de ferrocarriles de 1877 consagró la estructura radial bosquejada en la Ley General de los Ferrocarriles; las líncas MadridBarcelona y Zaragoza-Castejón-Irún estaban ya construídas, incrementando así en Aragón las posibilidades de los ejes del Ebro (aguas arriba de Zaragoza) y del Jalón, con el consiguiente beneficio para la capital, Zaragoza.

A fines del siglo XIX, en Aragón, además de las líneas férreas anteriormente citadas, están trazadas: la línea Valladolid-Ariza, que enlaza en esta localidad aragonesa con la línea Madrid-Barcelona, lo que supone un nuevo impulso para el valle del Jalón; la de Zaragoza a Jaca, que refuerza la situación de núcleos que, como Sabiñánigo, podrán con el tiempo industrializarse y urbanizarse; la de Zaragoza a Tarragona, vía Alcañiz y Caspe, que favorece los núcleos intermedios. En vísperas de la gucrra civil la red está prácticamente completa: la vía Zaragoza-Jaca ha sido prolongada ya hasta Canfranc; la depresión tectónica intraibérica es utilizada para la instalación de la línea Calatayud-Terucl-Valencia, que enlaza en Caminreal 
con la de Zaragoza; cl eje intraibérico se prolonga hacia el noroeste desde Calatayud hacia Soria. La existencia de ferrocarril en una localidad se convierte pronto en un factor fundamental para su desarrollo socioeconómico y su incorporación a la sociedad industrial.

\subsection{3.- El impacto de la revolución industrial}

Tardía, la revolución industrial permite en España la formación a lo largo del siglo XIX del triángulo geoeconómico español Madrid-Barcelona-País Vasco. El papel de Madrid en tanto que capital de un estado moderno y centralista se acentúa por el trazado radial de las nuevas carreteras y de las nuevas vías férreas; a su carácter de capital de la Administración Pública debe añadirse su función financiera y de servicios. Numerosas empresas nacidas en las provincias se aproximan a las residencias del poder político; un mercado de consumo creciente atrae poco a poco a las industrias de consumo. Pero la localización industrial, en el contexto de una política liberal, se concreta en el siglo XIX en Barcelona, que detenta el monopolio de la industria textil, y en el País Vasco, que centraliza la siderurgia. El proteccionismo nacido a finales del siglo XIX y mantenido durante varios decenio del XX consagró la localización privilegiada de Cataluña y el País Vasco.

La revolución industrial suscita en España, como en otros países, alteraciones en la jerarquía urbana que acentúan los desequilibrios entre la ciudad y las regiones, de suerte que va pasándose de un mapa, a un tiempo artesanal e industrial, en que la localización de las actividades se dispersa y reparte de manera más o menos homogénea, a otro, industrial, concentrado en los focos catalán y vasco. Más allá de estos, no existen sino algunos focos excepcionales: Valcncia, cuyo pasado artesanal, aprovechando su función portuaria, va soldándose paulatinamente al mundo industrial, o Zaragoza, que se beneficia de su posición en el centro del triángulo geoeconómico español para desarrollar una industria de transformación.

\section{2.- El sistema urbano estatal.}

La política centralista del Estado en la Administración Pública y en la red de carreteras, unida a la política -liberal primero y proteccionista después- en materia de localización industrial, explican, en muy buena medida, la evolución de las ciudades dominantes en el sistema urbano español. 
CUADRO II: POBLACION CENSADA EN LAS DIEZ PRIMERAS CIUDADES ESPAÑOLAS

\begin{tabular}{lrlllllll}
\hline Censo 1877 & Habs. & \multicolumn{2}{l}{ Censo 1900 Habs.1900-1877 } & \multicolumn{2}{c}{ Ccnso 1930 } & Habs. 1930-1900 \\
& & & & $\%$ & & $\%$ \\
\hline 1.Madrid & 397816 & Madrid & 539835 & 35.7 & Barcelona & 1005561 & 88.7 \\
2.Barcelona & 248943 & Barcelona & 533000 & 114.1 & Madrid & 952832 & 76.5 \\
3.Valencia & 145782 & Valcncia & 213550 & 46.5 & Valcncia & 320195 & 49.9 \\
4 Sevilla & 134318 & Scvilla & 148315 & 10.4 & Scvilla & 228729 & 54.2 \\
5.Málaga & 115882 & Málaga & 130109 & 12.3 & Málaga & 188010 & 44.5 \\
6.Murcia & 91805 & Murcia & 111539 & 21.5 & Zaragoza & 173987 & 75.5 \\
7.Zaragoza & 86276 & Zaragoza & 99118 & 14.9 & Bilbao & 161987 & 94.4 \\
8.Granada & 76005 & Bilbao & 83306 & 154.5 & Murcia & 158724 & 42.3 \\
9.Cádiz & 65028 & Granada & 75900 & -0.1 & Granada & 118179 & 55.7 \\
10.Valladolid & 52181 & Cádiz & 69382 & 6.7 & Córdoba & 103106 & 68.6 \\
& & & & & & & & \\
\hline
\end{tabular}

Hasta el Censo de 1877, las alteraciones en la cúspide de la jerarquía urbana española no son tan sustanciales como las que se aprecian en el transcurso de los últimos años del siglo XIX. En relación a los censos de finales del siglo XVIII, el de 1877 muestra un crecimiento importante de Madrid, que dobla ampliamente su población como consecuencia del centralismo; su preeminencia sobre el sistema es total e indiscutible, aunque Barcelona, sin llegar a doblar su población y gracias a la industria algodonera, tenga más de la mitad de la población de Madrid. El estancamiento de muchas de las grandes ciudades andaluzas es ya un hecho, sobre todo en el caso de Cádiz.

CUADRO III: CRECIMIENTO DE 1836 A $1877(\%)$

\begin{tabular}{lr}
\hline Madrid & 77.3 \\
Barcelona & 110.6 \\
Valencia & 118.5 \\
Sevilla & 47.4 \\
Málaga & 54.2 \\
Murcia & 7.1 \\
Zaragoza & 90.1 \\
Granada & $-\overline{7}$ \\
Cádiz & 0.7
\end{tabular}




$\begin{array}{ll}\text { Valladolid } & 155.1 \\ \text { Bilbao } & 159.8\end{array}$

Fuente: ARTOLA, M., La burguesía revolucionaria (1808-1874)

La industrialización del último tercio del siglo XIX ha supuesto para Barcelona mucho más que la duplicación de sus efectivos demográficos, pero también el crecimiento de las ciudades industriales del norte, en particular Bilbao, que aparece en el primer censo del siglo XX en el octavo lugar del ranking urbano nacional. Las ciudades del sur crecen apenas y Granada pierde población incluso. En Levante, la capital de las "huertas", Murcía, en tanto que capital de una provincia minera, y Valencia, con su actividad portuaria y sus transformaciones industriales, mantienen su ritmo alcista. Zaragoza, con su industrialización naciente, parece un poco más dinámica que las capitales de provincia andaluzas. Pero la consecuencia más destacada que se desprende del último tercio del siglo XIX es la forma bicéfala que comienza a exhibir el sistema urbano español: Madrid, capital política; Barcelona, capital económica. Algo parecido a lo que sucede en Italia con Roma y Milán. La bicefalia se mantendrá hasta la guerra civil española; en el Censo de 1930, Barcelona sobrepasará incluso a Madrid en tamaño poblacional, alcanzando el millón de habitantes.

Durante el primer tercio del siglo $\mathrm{XX}$, los ritmos de crecimiento de las ciudades españolas de mayor tamaño son más uniformes. Lo que resalta en los porcentajes máximos, junto a los de Madrid, Barcelona y Bilbao, es al aumento demográfico de Zaragoza, subordinado al de los anteriores por el hecho de su posición espacial. Como consecuencia de la industrialización, Zaragoza y Bilbao sobrepasan a Murcia: la euforia minera declina.

En conjunto, la cúspide de la jerarquía urbana se refuerza, de suerte que, si en 1877 las diez mayores ciudades representan alrededor del 8,5\% de la población española, en 1900 constituyen el $10,7 \%$ y el $14,5 \%$ en 1930 . Es cierto que el proceso de urbanización afecta a todas las capitales de provincia, que totalizan en 1877 el $13,5 \%$ de la población española, el $16,9 \%$ en 1900 y el $21,6 \%$ en 1930. Esta evolución de los porcentajes nos lleva a corroborar algo que habíamos insinuado ya con anterioridad: con el transcurso de los años, la división provincial refuerza el papel del lugar central de las nuevas capitales frente a otras ciudades similares, lo que parece favorecer la formación lenta de pequeños subsistemas provinciales, deformados por los ejes que se orientan hacia Madrid o a ciudades que, como Zaragoza, han tenido algunas competencias administrativas supraprovinciales, o hacia ciudades desarrolladas primero sobre la industria y luego sobre su sector terciario, cual es el caso de Barcelona. 


\section{3.- La aparición de subsistemas provinciales en Aragón.}

En Aragón, el crecimiento de las ciudades está condicionado por los factores ya señalados. Desde 1833, Huesca y Teruel, por razones que residen en el hecho de su capitalidad provincial, detentan la primacía sobre el resto de las pequeñas ciudades de sus recientes demarcaciones. En Zaragoza, los factores de localización económicos, ya mencionados, y las competencias supraprovinciales tienen un peso mucho mayor.

\section{CRECIMIENTO PORCENTUAL DE LAS CAPITALES ARAGONESAS}

$\begin{array}{lcc} & 1836-1857 & 1836-1877 \\ \text { Huesca } & 16.9 & 32.6 \\ \text { Teruel } & 27.1 & 26.8 \\ \text { Zaragoza } & 42.5 & 90.1\end{array}$

Pero existen otras ciudades aragonesas que obtienen provecho de la estructura radial de las comunicaciones estatales. De este modo, Calatayud, sobre la vía Madrid-Zaragoza-Barcelona, conservará en 1860 su puesto como segunda ciudad de Aragón, delante de las nuevas capitales provinciales. En contraposición, Tarazona, que era en 1786 la tercera ciudad en cuanto a población, marginada de los ejes radiales, es sobrepasada por Teruel y Huesca en 1860.

En conjunto, el rank-size de 1860 nos muestra una primacía zaragozana mayor que en 1786, en consonancia con el deterioro del sistema urbano aragonés, que presenta signos de disfuncionalidad frente a los subsistemas provinciales que comienzan a hacer acto de presencia (Cuadro $\mathrm{n}^{\circ}$ IV).

CUADRO IV: "RANK-SIZE" DE LA REgION ARAGONESA. 1860

\begin{tabular}{lcccc}
\hline$N^{\circ}$ CIUDAD & POBL REAL & TEORICA & $\begin{array}{c}\text { DESVIACION } \\
\text { ABSOLUTA }\end{array}$ & $\begin{array}{c}\text { DESVIACION } \\
\text { RELATIVA }\end{array}$ \\
\hline 1. Zaragoza & 67428 & 65840 & 1588 & 2.4
\end{tabular}




\begin{tabular}{|c|c|c|c|c|}
\hline 2.Calatayud & 12306 & 32920 & -20614 & -62.7 \\
\hline 3. Terucl & 10432 & 21947 & -11515 & -52.5 \\
\hline 4.Huesca & 10160 & 16460 & -6300 & -38.3 \\
\hline 5.Caspe & 9951 & 13168 & -3217 & -24.5 \\
\hline 6Tarazona & 8394 & 10973 & -2580 & -23.6 \\
\hline 7. Barbastro. & 7817 & 9406 & -1589 & -16.9 \\
\hline 8.Alcañiz & 7649 & 8230 & -581 & -7.1 \\
\hline 9.Fraga & 7013 & 7316 & -303 & -4.2 \\
\hline 10.Borja & 5771 & 6584 & -813 & -12.4 \\
\hline 11.Tamarite de Litera & 4668 & 5985 & -1318 & -22.1 \\
\hline 12.Monzón & 4628 & 5487 & -859 & -15.7 \\
\hline 13.Albalate del Arzobispo & 4399 & 5065 & -666 & -13.2 \\
\hline 14.Tauste & 4313 & 4703 & -390 & -8.3 \\
\hline 15.Ejea de los Caballeros & 4100 & 4389 & -290 & -6.6 \\
\hline 16.La Almunia de Dña. Godi & 4027 & 4115 & -88 & -2.2 \\
\hline 17.Epila & 3926 & 3873 & 53 & 1.3 \\
\hline 18.Jaca & 3915 & 3658 & 257 & 7.0 \\
\hline 19.Sos del Rey Católico & 3848 & 3465 & 382 & 11.0 \\
\hline 20.Calanda & 3815 & 3292 & 523 & 15.8 \\
\hline 21.Aleca & 3786 & 3135 & 650 & 20.7 \\
\hline 22.Maclla & 3420 & 2993 & 427 & 14.2 \\
\hline 23.Sariñena & 3340 & 2863 & 477 & 16.6 \\
\hline 24. Daroca & 3314 & 2743 & 570 & 20.8 \\
\hline 25.Híjar & 3306 & 2634 & 672 & 25.5 \\
\hline 26.Belchite & 3297 & 2532 & 764 & 30.1 \\
\hline 27.Graus & 3242 & 2439 & 803 & 32.9 \\
\hline 28.Cariñena & 3216 & 2351 & 864 & 36.7 \\
\hline 29.Sástago & 3207 & 2270 & 936 & 41.2 \\
\hline 30.Mora de Rubielos & 3016 & 2195 & 821 & 37.4 \\
\hline 31.Mosqueruela & 2982 & 2124 & 858 & 40.4 \\
\hline 32.Calaceite & 2952 & 2057 & 894 & 43.4 \\
\hline 33.Alagón & 2891 & 1995 & 895 & 44.9 \\
\hline 34.Pina & 2840 & 1936 & 903 & 46.6 \\
\hline 35.Mequinen $z a$ & 2822 & 1881 & 940 & 50.0 \\
\hline 36.Mallén & 2784 & 1829 & 955 & 52.2 \\
\hline 37.Almudévar & 2733 & 1779 & 953 & 53.5 \\
\hline 38.Escatrón & 2691 & 1733 & 958 & 55.3 \\
\hline 39.Ricla & 2687 & 1688 & 998 & 59.1 \\
\hline 40. Valderrobres & 2681 & 1646 & 1035 & 62.8 \\
\hline 41.Uncastillo & 2679 & 1606 & 1073 & 66.8 \\
\hline 42.Gclsa & 2626 & 1568 & 1058 & 67.5 \\
\hline
\end{tabular}


La red urbana aragonesa: entre el sistema urbano estatal y los...

43. Aycrbe

44.Samper de Calanda

45.Quinto

46.Magallón

47.Alcorisa

48. Castellote

49. Manzanera

50.Gallur

51.Benabarre

52.Fonz

53.Pedrola

54.Rubielos de Mora

55.Alcolea de Cinca

56.La Puebla de Híjar

57.Sarrión

58. Morata de Jalón

59.Azuara

60.Almonacid de la Sierra

61.Zuera

62. Castelserás

63.Aguarón

64.Bujaraloz

65.Ballobar

66. Fuentes de Ebro

67. Albarracín

68.Cella

69.Alcampel
2610

2601

2590

2579

2542

2479

2458

2414

2397

2363

2330

2330

2318

2274

2228

2226

2216

2204

2190

2180

2171

2163

2131

2090

2054

2030

2013
1531

1496

1463

1431

1401

1372

1344

1317

1291

1266

1242

1219

1197

1176

1155

1135

1116

1097

1079

1062

1045

1029

1013

998

983

968

954
1078

1104

1126

1147

1141

1107

1114

1097

1106

1096

1087

1110

1120

1098

1072

1090

1100

1106

1110

1118

1125

1134

1118

1092

1071

1061

1058
70.4

73.8

77.0

80.1

81.4

80.7

82.9

83.3

85.6

86.6

87.5

91.0

93.6

93.4

92.8

96.0

98.5

100.8

102.9

105.2

107.7

110.2

110.3

109.5

109.0

109.6

110.9

INDICE DE PRIMACIA $1=5,479$

INDICE DE PRIMACIA $2=2,965$

INDICE DE PRIMACIA $3=2,049$

INDICE DE PRIMACIA $4=1,573$

En la provincia de Zaragoza, como parece lógico, la primacía de la capital, sobre un conjunto que comporta hasta 34 localidades con población urbana o semiurbana, se mantiene; a partir de este momento, las cabeceras comarcales 
los pequeños núcleos semiurbanos tienen desviaciones positivas. Por el contrario, en las distribuciones de las provincias de Huesca y Teruel, las capitales e incluso las ciudades que les siguen tienen todavía un tamaño insuficiente.

En 1900, se acentúa la macrocefalia de Zaragoza, que es ya siete veces mayor que Huesca -la segunda ciudad aragonesa ahora-; precisamente, es la condición de capital provincial lo que permite a ésta última sobrepasar a Calatayud y aproximarse a Teruel. El crecimiento demográfico general afecta a los núcleos urbanos y semiurbanos aragoneses (las localidades de más de 2.000 habitantes) que, si en 1786 eran 33 y 69 en 1860 , son 75 en 1900 , agrupando a más del $40 \%$ de la población aragonesa (Cuadro № V).

\section{CUADRO V: "RANK-SIZE" DE LA REgION ARAGONESA. 1900}

\begin{tabular}{|c|c|c|c|c|c|}
\hline $\mathrm{N}^{2}$ & CIUDAD & POBL REAL & TEORICA & $\begin{array}{c}\text { DESVIACION } \\
\text { ABSOLUTA }\end{array}$ & $\begin{array}{l}\text { DESVIACION } \\
\text { RELATIVA }\end{array}$ \\
\hline 1. & Zaragoza & 99118 & 73733 & 25385 & 34.4 \\
\hline 2. & Huesca & 12626 & 36866 & -24240 & 65.8 \\
\hline 3. & Calatayud & 11526 & 24578 & -13052 & 53.2 \\
\hline 4. & Teruel & 10706 & 18433 & -7727 & -42.0 \\
\hline 5. & Tarazona & 8790 & 14747 & -5957 & -40.4 \\
\hline 6. & Alcañiz & 7806 & 12289 & -4483 & -36.5 \\
\hline 7. & Caspe & 7735 & 10533 & -2799 & -26.6 \\
\hline 8. & Barbastro & 7033 & 9217 & -2184 & -23.7 \\
\hline 9. & Fraga & 6809 & 8193 & -1384 & -16.9 \\
\hline 10. & Borja & 5701 & 7373 & -1673 & -22.7 \\
\hline 11. & Jaca & 4934 & 6703 & -1769 & -26.4 \\
\hline 12. & Tauste & 4630 & 6144 & -1515 & -24.7 \\
\hline 13. & Ejea de los Caballeros & 4627 & 5672 & -1045 & -18.5 \\
\hline 14. & Albalate del Arzobisp & 4220 & 5267 & -1047 & -19.9 \\
\hline 15. & La Almunia de Doña & Jodina 3948 & 4916 & -968 & -19.7 \\
\hline 16. & Calanda & 3876 & 4608 & -733 & -15.9 \\
\hline 17. & Tamarite de Litera & 3867 & 4337 & -471 & -10.9 \\
\hline 18. & Monzón & 3829 & 4096 & -268 & -6.6 \\
\hline 19. & Alagón & 3745 & 3881 & -136 & -3.5 \\
\hline 20. & Epila & 3669 & 3687 & -18 & -0.5 \\
\hline
\end{tabular}




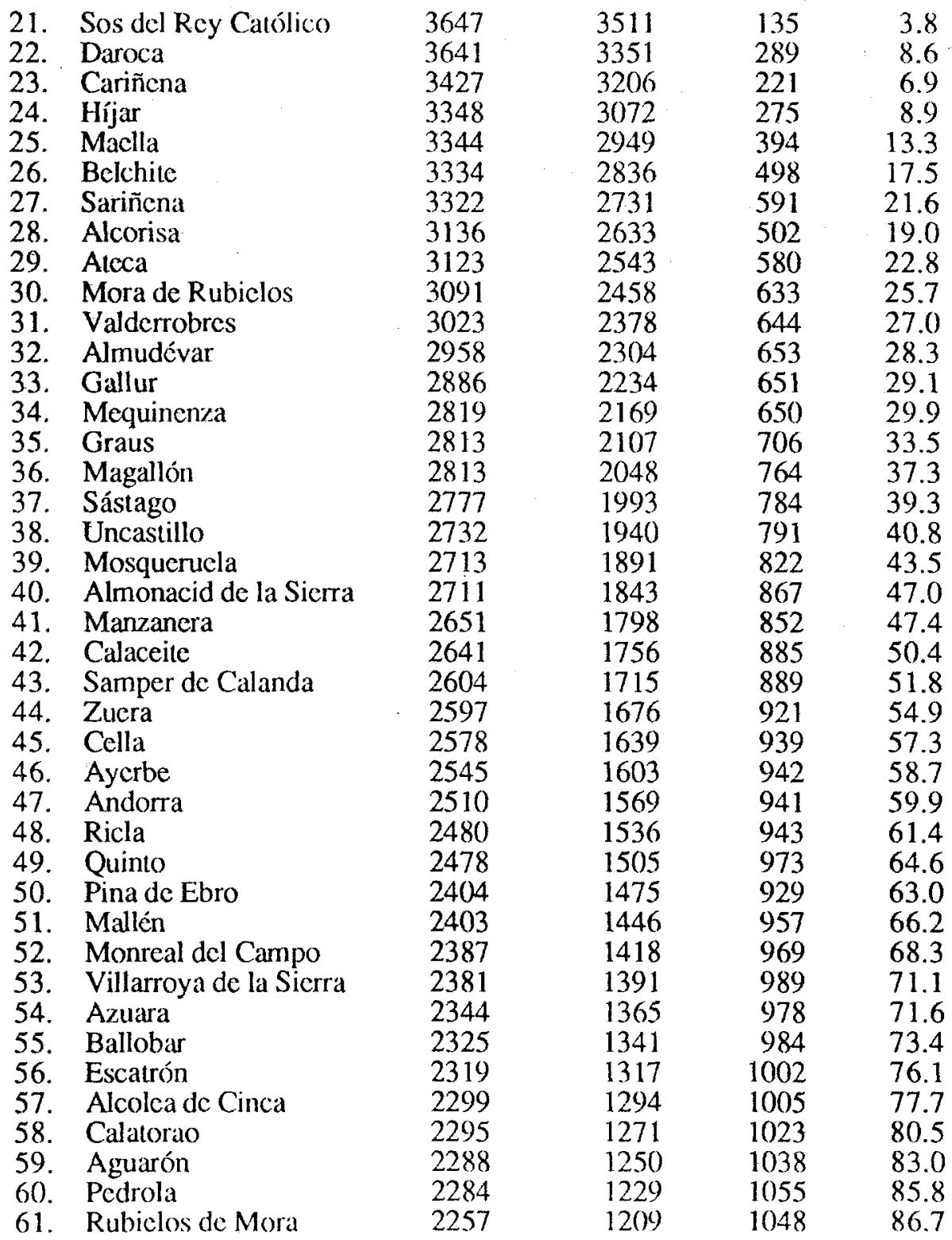


62. Fuentes de Ebro

\section{3}

2186

1189

1170

1013

85.2

63. Oliete

2168

1152

1015

86.7

64. Sarrión

2158

1134

1015

88.1

65. Beceite

2156

1023

90.2

66. Morata de Jalón

1117

1038

92.9

67. Castelserás

1100

1006

91.4

2091

1006

1069

92.8

69. Castellote

2086

1017

95.2

70. Torrijo

2076

1053

1022

2070

1031

97.0

71. Gelsa

2064

1038

99.3

72. Ainzón

2039

73. Fabara

2032

1024

1039

101.5

74. Fonz

75. Montalbán

2030

TOTAL POBLACION

361390

996

983

1028

101.8

1035

1046

103.9

106.4

INDICE DE PRIMACIA $1=7,85$

INDICE DE PRIMACIA $2=4,103$

INDICE DE PRIMACIA $3=2,843$

INDICE DE PRIMACIA $4=2,27$

En el subsistema zaragozano de 1900, la preeminencia de Zaragoza es todavía más importante que en el conjunto de Aragón, mientras Calatayud pierde su segundo lugar; en el resto de la jerarquía continúan existiendo los mismos problemas que en 1860 .

En los nacientes subsistemas provinciales de Huesca y Teruel de 1900, Huesca presenta una preeminencia más próxima a la teoría que Teruel, poco dinámica hacia el último tercio del siglo XIX.

En 1930, Calatayud sobrepasa de nuevo a las capitales provinciales gracias al desarrollo de las comunicaciones y del comercio.

CUADRO VI: RANGO-TAMAÑO, 1930.

1. Zaragoza

173967

2. Calatayud

15168

3. Huesca

14632

4. Teruel

13584 
5. Caspe

6. Tarazona

9605

7. Alcañiz

8823

8. Ejca de los Caballeros

7800

9. Fraga

10. Jaca

11. Barbastro

6601

12. Tauste

6182

13. Borja

5013

\section{3.- INCIDENCIA DE LA POLITICA DEL REGIMEN FRANQUISTA SOBRE EL SUBSISTEMA URBANO}

\section{1.- Los factores.}

\subsection{1.- La política industrial.}

El centralismo borbónico y napoleónico se acentúa durante una buena parte del régimen de Franco. En el curso de los primeros años y en un contexto autárquico, Madrid, centro de decisión política, alrae la localización de las actividades económicas: los permisos de importación de materias primas o de bienes de equipo, por ejemplo, son concedidos más fácilmente cuanto más cerca se está del Ministerio de Comcrcio; el Instituto Nacional de Industria invierte en Madrid; el creciente mercado de consumo atrae nuevas industrias, etc... En el transcurso de los años cuarenta, Madrid comienza su verdadero despegue industrial. Durante este tiempo, los focos industriales ya existentes en Cataluña y el País Vasco, en pleno período de política proteccionista y autárquica y sin grandes compelencias, crecen todavía más.

La política de desarrollo, a partir de 1964, intenta una diversificación espacial de la industria española y una disminución de los desequilibrios regionales, mediante la creación de polos de desarrollo industrial (Zaragoza, Sevilla, Valladolid, La Coruña y Vigo) y de promoción industrial (Huelva, Burgos). 
V. Bielza, J. Callizo y S. Escolano

CUADRO VII: "RANK-SIZE" DE LA REGION ARAGONESA. 1950

\begin{tabular}{|c|c|c|c|c|c|}
\hline $\mathrm{N}^{\circ}$ & CIUDAD & REAL & TEORICA & $\begin{array}{l}\text { DESVIACION } \\
\text { ABSOLUTA }\end{array}$ & $\begin{array}{l}\text { DESVIACION } \\
\text { RELATIVA }\end{array}$ \\
\hline 1. & Zaragoza & 244015 & 115974 & 128040 & 110,6 \\
\hline 2. & Huesca & 20003 & 57987 & -37985 & $-65,6$ \\
\hline 3. & Calatayud & 18318 & 38659 & -20341 & $-52,7$ \\
\hline 4. & Teruel & 18023 & 28994 & -10971 & $-37,9$ \\
\hline 5. & Taraziona & 11988 & 23195 & -11207 & $-48,4$ \\
\hline 6. & Caspe & 10128 & 19329 & -9202 & $-47,7$ \\
\hline 7. & Alcañiz & 9812 & 16568 & -6756 & $-40,8$ \\
\hline 8. & Ejea de los Caballeros & 8729 & 14497 & -5768 & $-39,8$ \\
\hline 9. & Barbastro & 8144 & 12886 & -4743 & $-36,8$ \\
\hline 10. & Jaca & 7754 & 11597 & -3844 & $-33,2$ \\
\hline 11. & Fraga & 7750 & 10543 & -2794 & $-26,5$ \\
\hline 12. & Tauste & 6565 & 9665 & -3100 & $-32,1$ \\
\hline 13. & Monzón & 5622 & 8921 & -3300 & $-37,0$ \\
\hline 14. & Alagón & 5484 & 8284 & -2800 & $-33,8$ \\
\hline 15. & Epila & 5462 & 7732 & -2270 & $-29,4$ \\
\hline 16. & Borja & 5024 & 7248 & -2225 & $-30,7$ \\
\hline 17. & Zuera & 4793 & 6822 & -2030 & $-29,8$ \\
\hline 18. & Tamarite de Litera & 4594 & 6443 & -1850 & $-28,7$ \\
\hline 19. & Binéfar & 4571 & 6104 & -1533 & $-25,2$ \\
\hline 20. & Andorra & 4472 & 5799 & -1327 & $-22,9$ \\
\hline 21 . & Albalate del Arzobispo & 4341 & 5523 & -1182 & $-21,4$ \\
\hline 22. & La Almunia de Dña. Godina & 4273 & 5272 & -999 & $-19,0$ \\
\hline 23. & Gallur & 4038 & 5042 & -1005 & $-20,0$ \\
\hline 24. & Cella & 3909 & 4832 & -924 & $-19,2$ \\
\hline 25. & Daroca & 3786 & 4639 & -853 & $-18,4$ \\
\hline 26. & Mequinenza & 3754 & 4461 & -707 & $-15,9$ \\
\hline 27. & Belchite & 3589 & 4295 & -707 & $-16,5$ \\
\hline 28. & Híjar & 3586 & 4142 & -556 & $-13,5$ \\
\hline 29. & Monreal del Campo & 3554 & 3999 & -446 & $-11,2$ \\
\hline 30. & Calanda & 3544 & 3866 & -322 & $-8,4$ \\
\hline 31. & Ateca & 3410 & 3741 & -332 & $-8,9$ \\
\hline 32. & Calatorao & 3410 & 3624 & -215 & $-6,0$ \\
\hline 33. & Almudćvar & 3265 & 3514 & -250 & $-7,1$ \\
\hline 34. & Alcorisa & 3208 & 3411 & -204 & $-6,0$ \\
\hline
\end{tabular}



La red urbana aragonesal cntre el sistema urbano estatal y los...

35. Sariñena

36. Mallén

37. Cariñena

38. Escalrón

39. Uncastillo

40. Sos del Rey Católico

41. Graus

42. Maclla

43. Ariza

44. Fuentes de Ebro

45. Ricla

46. Calamocha

47. Morata de Jalón

48. La Puebla de Híjar

49. Pedrola

50. Valderrobres

51. Sádaba

52. Montalbán

53. Sástago

54. Utcbo

55. Santa Eulalia

56. Azuara

57. Ayerbe

58. Quinto

59. Samper de Calanda

60. Cetina

61. Lécera

62. Pina

63. Binaced

64. Mora de Rubielos

65. Gurrea de Gállego

66. Sabiñánigo

67. Villanueva de Gállego

68. Luna

69. Calaceitc

70. Alhama de Aragón

71. Magallón

72. Lumpiaque

73. Gclsa

74. Fon\%

TOTAL POBLACION

$\begin{array}{ll}3183 & 3314 \\ 3177 & 3222 \\ 3158 & 3134 \\ 3156 & 3052 \\ 3120 & 2974 \\ 3068 & 2899 \\ 3061 & 2829 \\ 3020 & 2761 \\ 2987 & 2697 \\ 2962 & 2636 \\ 2829 & 2577 \\ 2816 & 2521 \\ 2786 & 2468 \\ 2738 & 2416 \\ 2702 & 2367 \\ 2697 & 2319 \\ 2686 & 2274 \\ 2672 & 2230 \\ 2658 & 2188 \\ 2652 & 2148 \\ 2649 & 2109 \\ 2593 & 2071 \\ 2506 & 2035 \\ 2443 & 2000 \\ 2408 & 1966 \\ 2407 & 1933 \\ 2395 & 1901 \\ 2309 & 1871 \\ 2300 & 1841 \\ 2276 & 1812 \\ 2266 & 1784 \\ 2249 & 1757 \\ 2138 & 1731 \\ 2136 & 1706 \\ 2122 & 1681 \\ 2064 & 1657 \\ 2044 & 1633 \\ 2031 & 1611 \\ 2022 & 1589 \\ 2014 & 1567 \\ 568432 & \\ & \end{array}$

$-131$

$-45$

23

104

146

168

232

258

289

326

251

294

318

321

335

377

411

441

469

504

540

522

471

443

442

474

493

438

459

463

481

491

407

430

441

407

410

420

433

446
$-4,0$

$-1,4$

0,7

3,4

4,9

5,8

8,2

9,3

10,7

12,3

9,7

11,6

12,9

13,3

14,1

16,2

18,1

19,8

21,4

23,4

25,6

25,2

23,1

22,1

22,5

24,5

25,9

23,4

24,9

25,6

27,0

27,9

23,5

25,2

26,2

24,5

25,1

26,0

27,2 


$\begin{array}{lc}\text { INDICE DE PRIMACIA } 1= & 12,198 \\ \text { INDICE DE PRIMACIA } 2= & 6,367 \\ \text { INDICE DE PRIMACIA } 3= & 4,33 \\ \text { INDICE DE PRIMACIA 4 }= & 3,571\end{array}$

En realidad, lo que se obtiene -gracias a una cierta diversificación industrial- es una aproximación de los niveles de renta per capita entre las ciudades de los polos y las ciudades industrializadas con anterioridad, mientras que los demás niveles jerárquicos de las redes urbanas de Aragón, Andalucía, Castilla la Vieja y Galicia no consiguen salir del estancamiento. Estos polos estatales, y los que les siguen, no han funcionado como focos de irradiación de flujos de desarrollo hacia sus regiones respectivas, sino que, por el contrario, han provocado un crecimiento casi exclusivamente local, macrocéfalo y congestivo, que ha dado lugar a numerosos problemas de alojamiento, escolarización, especulación del suelo urbano, tráfico y, lo que es peor, de inadaptación de la población inmigrada.

\subsection{2. - La política de transporte.}

En el decurso de las últimas décadas, se ha reforzado el sistema radial de comunicaciones terrestres, favoreciendo así el sistema urbano estatal y soslayando los subsistemas urbanos regionales y los desequilibrios socioeconómicos regionales. No otra cosa significa, por ejemplo, que el Plan de la Red de Itinerarios Asfálticos (REDIA), con el fin de mejorar el trazado y las características de las carreteras, se concentre, de 1967 a 1971, sobre 5.000 $\mathrm{Km}$, que corresponden a los tramos de más intenso tráfico; dicho de otra manera: todavía una vez más, la red radial y los ejes mediterráneo (La Junquera-Alicante) y Cantábrico (Irún-Oviedo). En Aragón, zona de paso, la Nacional II (Madrid-Zaragoza-Barcelona) es la única afectada.

El trazado de las autopistas españolas no cuenta, en 1980, más que con dos grandes ejes: el del Mediterráneo y el del Ebro, que comunica con el tramo litoral vasco Bilbao-Behovia. Esto supone la interconexión de las regiones más industrializadas, que aumentan su ventaja sobre el resto. Una vez más, Zaragoza ve reforzado su poder en relación al resto de Aragón, y esto, en función de las regiones industriales españolas que son, hasta el presente, las más importantes. En el caso de las autopistas, como es sabido, el multiplicador puntual (Zaragoza) acentúa la axialidad (eje del Ebro), lo que hace que los desequilibrios intrarregionales se agraven. 
Los ferrocarriles persiguen, en el curso de los últimos decenios, una política que privilegia los ejes radiales, diferenciando la red de base de las redes complementaria y secundaria. En Aragón, la red de base se reduce a la línea Madrid-Zaragoza-Tarragona-Barcelona y al eje Zaragoza-Logroño. La política de desarrollo regional promovida a partir de los polos de desarrollo, en el transcurso de los años sesenta, no utilizó el ferrocarril, y la prueba está en que los polígonos industriales de Malpica y Cogullada no fueron dotados de acceso a la red ferroviaria.

Finalmente, es impensable que el transporte aéreo pueda tener un impacto intrarregional en nuestro pais, dadas las características de este medio de transporte. Es más, este medio de transporte ha favorecido a las grandes ciudades en detrimento de las demás y ha estrechado sus relaciones con Madrid y Barcelona. Es el caso de Zaragoza, cuyos vuelos tienen por destino, de una manera no exclusiva pero sí predominante, esas dos grandes metrópolis.

\section{2.- El sistema urbano estatal.}

En la evolución de la cima de la jerarquía urbana española, y a la vista de los factores enunciados, se observan los siguientes hechos:

a) La superación de la bicefalia en beneficio de la primacía de Madrid sobre Barcelona, que desempeña a pesar de todo un papel más importante en el momento presente que el de las otras metrópolis regionales españolas.

b) Un ajuste relativo a la regla "rango-tamaño" en la cabeza del sistema urbano español, sobre el que no vamos a insistir aquí, puesto que ha sido ya suficientemente tratado por otros autores: Capel (1974), Díez Nicolás (1972), Ferrer Regales (1972), Lasuén (1976), etc...

c) Continuación del proceso de pérdida de rango de las ciudades andaluzas no industrializadas.

d) Las ciudades de lo polos se encuentran, entre 1950 y 1981 , entre las de mayor crecimiento, en particular Zaragoza y Valladolid.

CUADRO VIII: POBLACION DE LAS PRIMERAS CAPITALES ESPAÑOLAS. AÑOS 1930, 1950, 1960, 1970 Y 1981.

\begin{tabular}{lrrrrr}
\hline CAPITALES & 1930 & 1950 & 1960 & 1970 & 1981 \\
\hline Madrid & 952832 & 1618435 & 2298410 & 3095518 & 3188297
\end{tabular}




\begin{tabular}{lrrrrr} 
Barcclona & 1005565 & 1280179 & 1567267 & 1735858 & 1754900 \\
Valencia & 320195 & 509075 & 511797 & 645536 & 751734 \\
Sevilla & 228729 & 376627 & 447220 & 542413 & 653833 \\
Málaga & 188010 & 276322 & 304454 & 370516 & 503251 \\
Murcia & 158724 & 218375 & 249521 & 244138 & 288631 \\
Zaragoza & 173987 & 264256 & 332782 & 470843 & 590750 \\
Granada & 118179 & 154378 & 158747 & 188675 & 262182 \\
Cádiz & 78264 & 100249 & 118747 & 134834 & 157766 \\
Valladolid & 91089 & 124212 & 155257 & 231246 & 330242 \\
Bilbao & 161987 & 229334 & 308858 & 404103 & 433030 \\
Córdoba & 103106 & 165403 & 199940 & 233680 & 284737 \\
\hline
\end{tabular}

\section{CRECIMIENTO PORCENTUAL DE LAS PRIMERAS CAPITALES ESPAÑOLAS}

\begin{tabular}{lrrrrr} 
CAPITALES & $1930-50$ & $1950-60$ & $1960-70$ & $1970-81$ & $1877-1981$ \\
\hline Madrid & 69,85 & 42,01 & 34,68 & 2,99 & 701,45 \\
Barcelona & 27,30 & 22,42 & 10,75 & 1,09 & 604,94 \\
Valencia & 58,98 & 0,53 & 26,13 & 16,45 & 415,65 \\
Sevilla & 64,66 & 18,74 & 21,28 & 20,54 & 386,77 \\
Málaga & 46,97 & 10,18 & 21,69 & 35,82 & 334,27 \\
Murcia & 37,58 & 14,26 & $-2,15$ & 18,22 & 214,39 \\
Zaragoza & 51,88 & 25,93 & 41,48 & 25,46 & 584,72 \\
Granada & 30,63 & 2,83 & 18,85 & 38,95 & 244,95 \\
Cádiz & 28,09 & 18,45 & 13,54 & 17,00 & 142,61 \\
Valladolid & 36,36 & 24,99 & 48,94 & 42,80 & 532,87 \\
Bilbao & 41,57 & 34,67 & 30,83 & 7,15 & 1222,87 \\
Córdoba & 60,42 & 20,88 & 16,87 & 21,84 & 472,27 \\
\hline
\end{tabular}

\section{3.- Aragón y los subsistemas provinciales.}

A escala intrarregional, los factores anteriormente citados para el nivel estatal, directamente incidentes sobre los sectores secundario y terciario, no son los únicos capaces de explicar las alteraciones del ranking urbano. En regiones como Aragón, no podemos olvidar la influencia de la política de 
nuevos regadíos para comprender el ascenso de ciudades agrícolas como Ejea de los Caballeros, que a fines del siglo XVIII ocupaba el $20^{\circ}$ lugar en la jerarquía de los asentamientos aragoneses y hoy el $5^{\circ}$, y en el subsistema de la provincia de Zaragoza el $3^{\circ}$. Los núcleos industriales y mincros crecen también de manera importante. En la provincia de Hucsca, Monzón ocupaba en 1950 el $6^{\circ}$ lugar y en 1981 el $2^{\circ}$; Sabiñánigo era en 1900 poco más que una aldea perdida que no figuraba en el ranking, en 1950 era el $14^{\circ}$ y hoy el $6^{\circ}$. En la provincia de Teruel, Andorra ha pasado del $14^{\circ}$ lugar en 1950 al $3^{\circ} \mathrm{en}$ 1950 y en 1981; Utrillas, como Sabiñánigo, no figuraba en el ranking en. 1900 , en 1950 era el $21^{\circ}$ y en 1981 el $5^{\circ}$. En la provincia de Zaragoza, los ascensos más destacables son los de los núcleos industrializados en torno a la capital: Utebo ha pasado del puesto $63^{\circ}$ en 1900 al $7^{\circ}$ en $1981 ; Z u e r a$, del $23^{\circ}$ al $8^{\circ}$. Por el contrario, hay muchas cabeceras comarcales históricas que se han estancado (Tarazona, Caspe, Calatayud,...) o hundido (Daroca, Borja, Sos,...).

En conjunto, el "sistema" urbano aragonés, heredero del pasado, tiene actualmente menos equilibrio y coordinación que los subsistemas provinciales, concebidos lentamente desde el siglo XIX. Zaragoza ha continuado creciendo y acentuando su macrocefalia en relación al resto de Aragón. Podemos escribir que existe una "desjerarquización" según el ranksize de 1981; que existe un vacío entre la metrópoli regional teórica y las pequeñas ciudades y pueblos; hay una carencia de ciudades medias y es mínimo el dinamismo de las pequeñas. Zaragoza ha crecido, no en función de Aragón, sino, mucho antes, del cuadrante nordeste español; su armonía en el seno del sistema urbano estatal contrasta por ello con su macrocefalia regional.

\section{CUADRO IX: "RANK-SIZE" DE LA REGION ARAGONESA.} 1981

\begin{tabular}{|c|c|c|c|c|c|}
\hline \multirow[b]{2}{*}{$N^{9}$} & \multirow[b]{2}{*}{ CIUDAD } & \multirow[b]{2}{*}{ POBL REAL } & \multirow[b]{2}{*}{ TEORICA } & \multicolumn{2}{|c|}{ DESVIACION DESVIACION } \\
\hline & & & & ABSOLUTA & RELATIVA \\
\hline 1. & Zaragoza & 571855 & 198832 & 373023 & 187,6 \\
\hline 2. & Huesca & 41455 & 99416 & -57961 & $-58,4$ \\
\hline 3. & Teruel & 25935 & 66277 & -40343 & $-60,9$ \\
\hline 4. & Calatayud & 17666 & 49708 & -32042 & $-64,5$ \\
\hline 5 & Ejea de los Caballeros & 15842 & 39766 & -23925 & $-60,2$ \\
\hline 6. & Monzón & 14861 & 33139 & -18278 & $-55,2$ \\
\hline 7. & Barbastro & 14536 & 28405 & -13869 & $-48,9$ \\
\hline
\end{tabular}




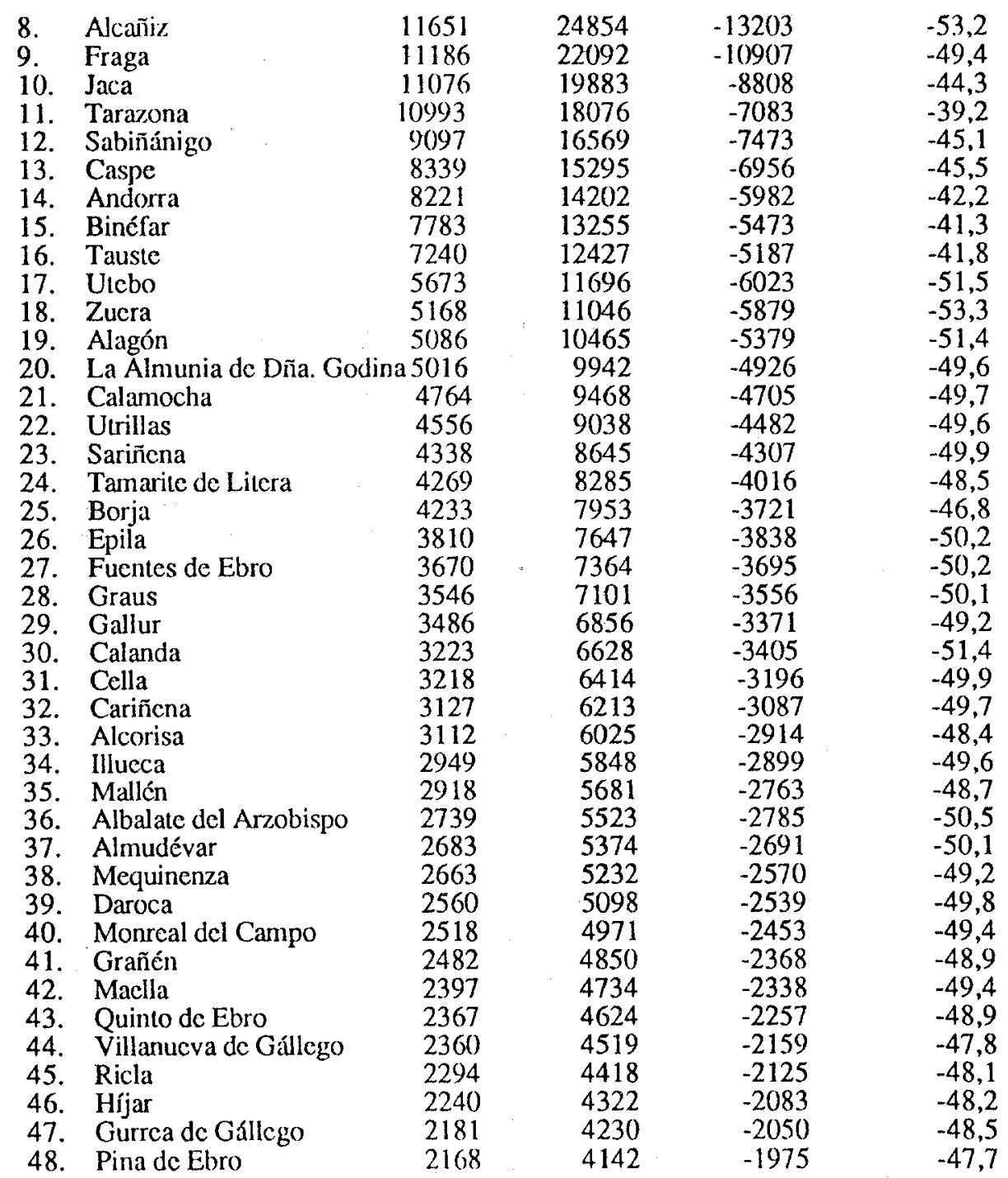


49. Pedrola

50. Montalbán

51. Ateca

52. Brea de Aragón

53. Sádaba TOTAL POBLACION
2143

2135

2131

2065

2034

906058
4058

3977

3899

3824

3752
$-1915$

$-1842$

$-1768$

$-1759$

$-1718$
$-47,2$

$-46,4$

$-45,4$

$-46,0$

$-45,8$
13,794

8,485

6,723

5,667

En el interior de los subsistemas provinciales, el más equilibrado es el de Huesca, que deja ver una distribución bastante próxima al rank-size teórico. Las curvas de Teruel, dada la regresión general de la provincia, muestran un subsistema que deja mucho que desear: deficiencia de población en general y de núcleos urbanos en particular. Los índices de primacía de las provincias de Huesca y Teruel estaban más próximos al modelo "rango-tamaño" en 1950 que en 1981, en que las capitales han crecido un poco más aprisa que la segunda ciudad respectiva; sin embargo, la situación actual no está muy lejos de la teórica, frente a lo que sucede en la provincia de Zaragoza, en que la curva real de 1981 se encuentra muy separada de la teórica o lognormal.

La conclusión que cabe hacer a la vista del examen de las alteraciones de los principios christallerianos (político-administrativo, comercial y de transporte) de organización del territorio, operadas desde el siglo XVIII y su incidencia en un tipo de relaciones sistemicas como las de rango-tamaño, es que la red urbana aragonesa, para fortalecerse como sistema a partir de su redefinición autonómica, precisa contar con las relaciones emanadas del sistema urbano estatal y de los subsistemas provinciales.

\section{NOTAS.:}

(1).- Según Vicens-Vives (Historia Económica de España), Barcelona tenía en 1723 una población de 35.000 habitantes, mientras que Madrid contaba 130.000; en 1797, Barcelona poseía 111.100 y Madrid 167.000.

(2). - Hemos tomado las localidades de más de 2.000 habitantes siguiendo el criterio del sistema censal español, que considera población semiurbana la 
de los municipios de tamaño superior a esa cifra. En Aragón, cabría hacer una distinción entre los Pirincos, donde los centros de más de 1.000 habitantes juegan el papel de lugarcs centrales, y los del llano del Valle del Ebro, en que los umbrales pueden estar entre 2.000 y 3.000 habitantes.

\section{BIBLIOGRAFIA}

ANES, G. (1979): "El Antiguo Régimen: los Borbones", en Historia de España Alfaguara, dirigida por M. Artola.- Tomo IV.- Madrid: Alianza Editorial, S.A. y Ediciones Alfaguara, S.A.

ARTOLA, M. (1973): La burguesía revolucionaria: 1808-1874.- Madrid: Alianza Editorial, S.A.

BIELZA DE ORY, V. (1976): "Las acciones necesarias para una regionalización eficaz y el área de influencia urbana", en Revista de Documentación Administrativa, 169, pp. 1-46.

CAPEL, H. (1974): Estudios sobre el sistema urbano.- Barcelona: Ediciones de la Universidad de Barcelona.

DERYCKE, P.H. (1970): L'économie urbaine.- Paris: P.U.F.

DESDEVISES DU DEZERT, G. (1897-1904): L'Espagne de l'Ancien Régime.- Paris: Société Française d'Imprimerie el de Librairie.

DIEZ NICOLAS, J. (1972): Especialización funcional y dominación en la España urbana.- Madrid: Publicaciones de la Fundación Juan MarchGuadarrama.

FERRER REGALES, M. (1972): "Un ejemplo de intcgración regional y sistemas urbanos en España", en Geographica, 3.

FULVI, F. (1985): "La rete urbana delle Marche", en Bolletino della Societa Geografica Italiana, Ser. XI, 1I, pp. 33-60.

GARCIA-NIETO GOMEZ GUILLAMON, A. (1983): "El sistema de ciudades en las regiones españolas según la regla 'rango-tamaño'", en Ciudad y Territorio, 55, pp. 43-54.

GUERRA ZABALLOS, A. (1981): "Los sistemas regionales españoles según el modelo 'rango-tamaño'", en Geographica, pp. 23-48.

LASUEN, J.R. (1976): Ensayos sobre economia regional y urbana.- Madrid: Instituto de Estudios de Administración Local.

LASUEN, J.R. (1986): El estado multi-regional. España descentrada..Madrid: Alianza Editorial, S.A.

MELON Y RUIZ DE GORDEJUELA, A. (1952): "El Mapa Prefectural de España (1810)", en Estudios Geográficos, 46, pp. 5-72.

MENENDEZ PIDAL, G. (1951): Los caminos en la historia de España.Madrid. 
MUÑOZ PEREZ, J. (1955): "Mapa aduancro del XVIII español", en Estudios Geográficos, 61, pp. 747-798.

PEREZ PRENDES, J.M. (1959): "Una visión de la administración central española en cl siglo XVIII", en Revista de la Facultad de Derecho de la Universidad de Madrid, VI, pp. 323-348.

QUIROS LINARES, F. (1971): Fuentes para la geografia de la circulación en España: algunos libros sobre los caminos españoles de los siglos XVIII y $X I X$.- Ovicdo.

ZIPF, G.K. (1949): Human behavior and the principle of least effort.Cambridge: Addison Wesley Press.

\section{FUENTES}

Censo Español executado de orden del Rey comunicada por el Excelentísimo Señor Conde de Floridablanca... Madrid, 1787 (microfilmado).

JUNTA DE ESTADISTICA GENERAL DEL REINO (1860): Nomenclátor de los pueblos de España.

I.N.E.: Censos de población de España, 1900, 1950 y 1981. 


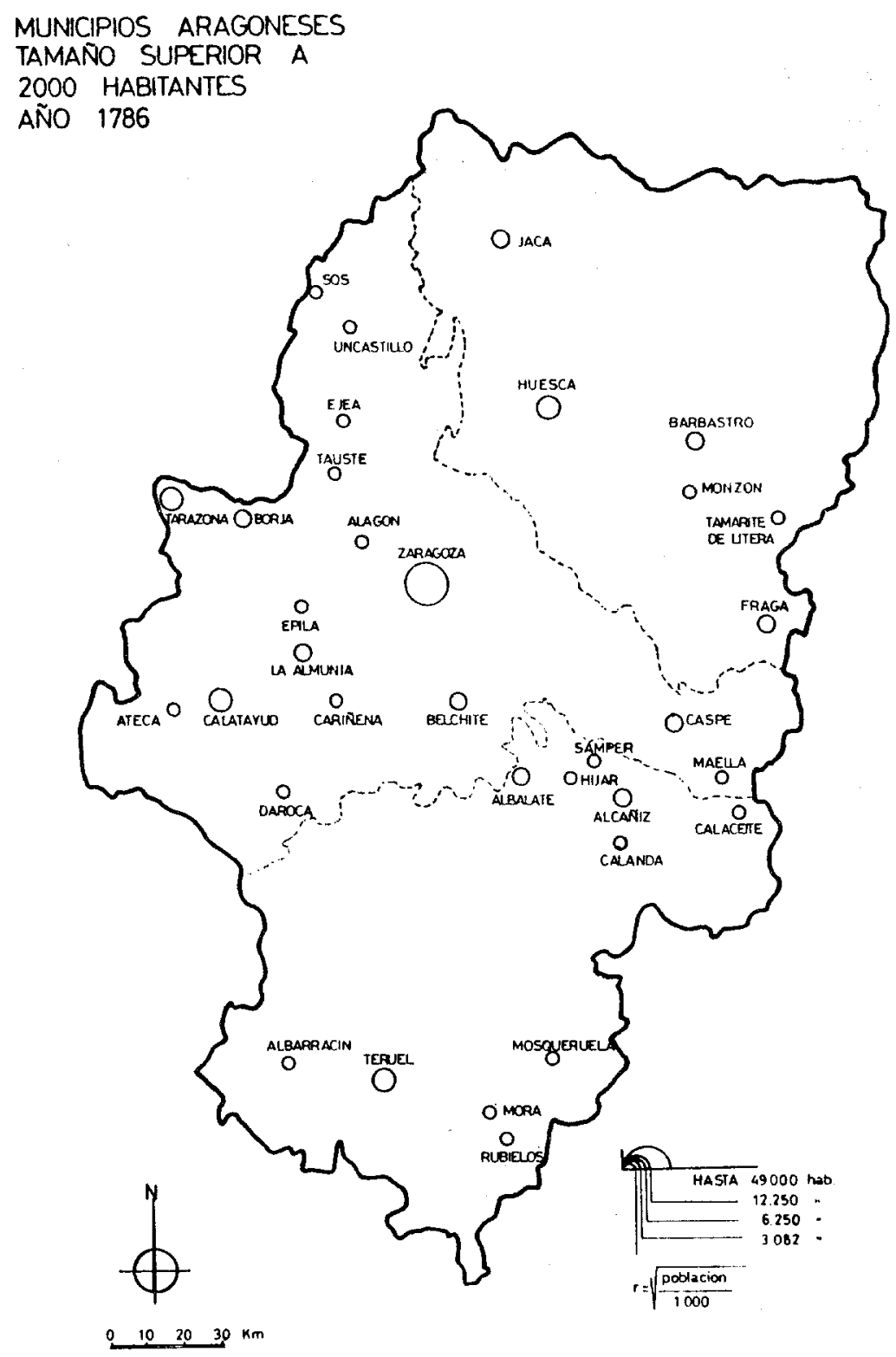




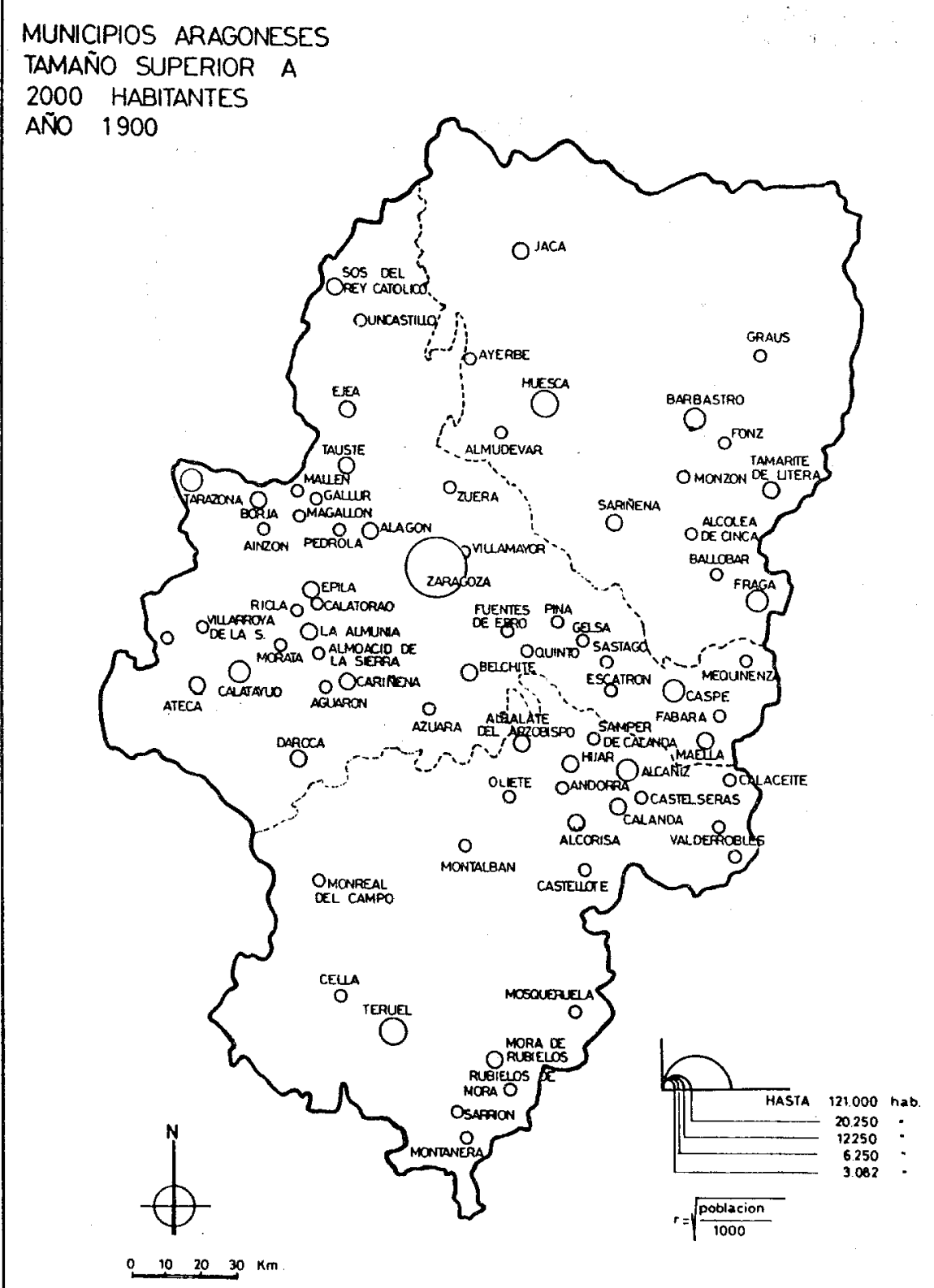




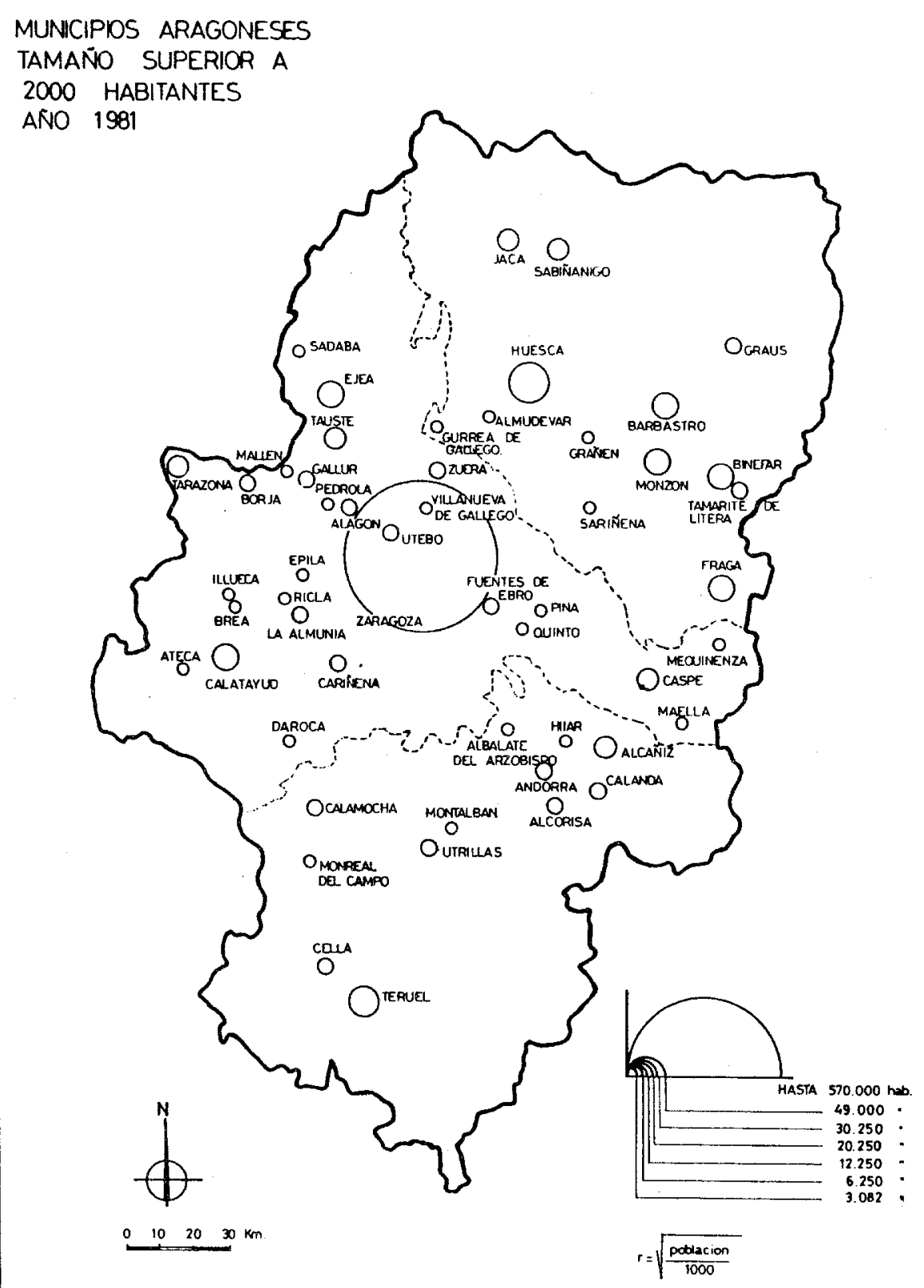


"RANK-SIZE" DE LA REGION ARAGONESA

1786,1900 y 1981

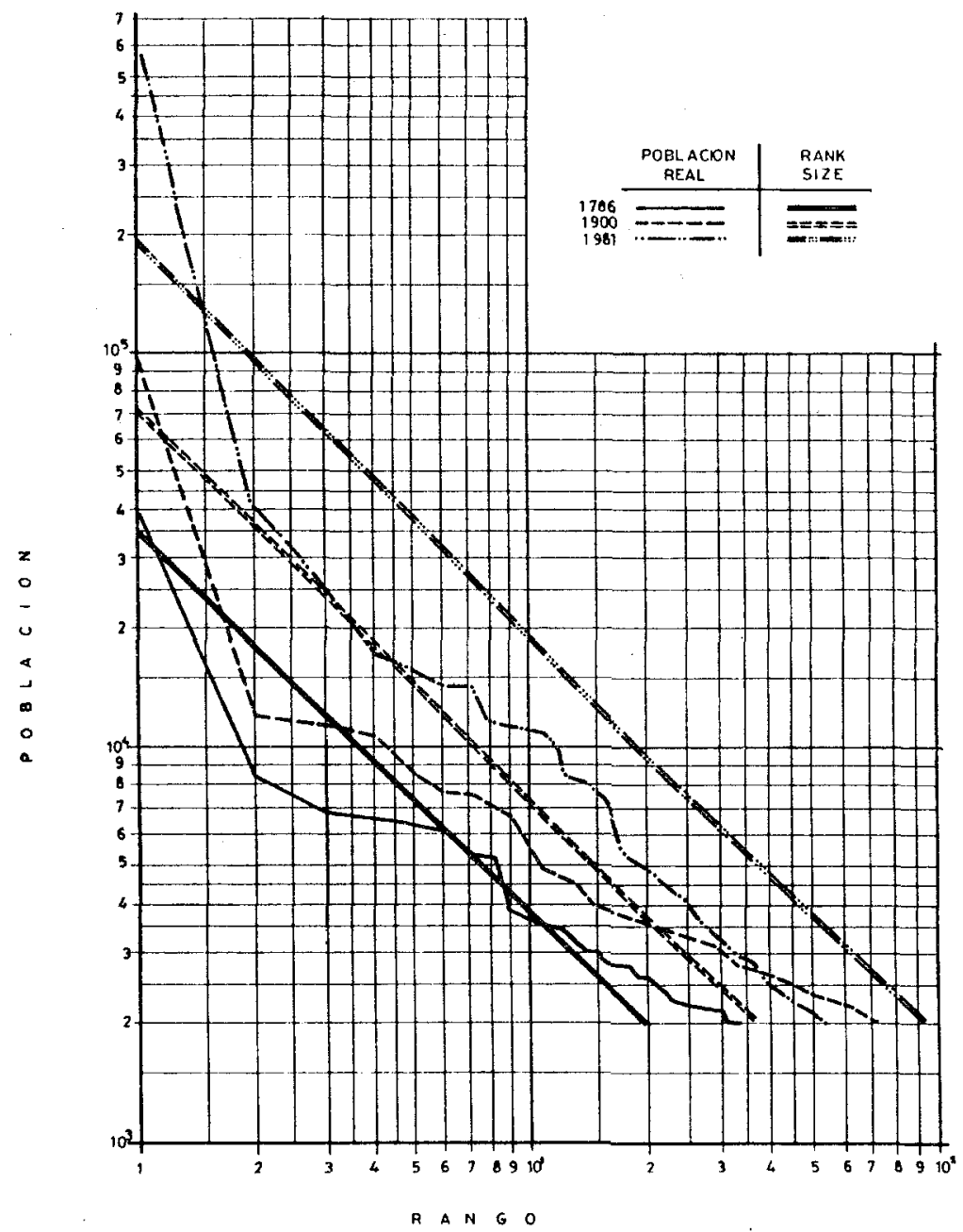

